Available online on 15.11.2017 at http://jddtonline.info
Open Access to Pharmaceutical and Medical Research
col1-17, publisher and licensee JDDT, This is an Open Access article which permits unrestricted non-
commercial use, provided the original work is properly cited

Open $\odot$ Access

Research Article

\title{
FORMULATION AND EVALUATION OF DOCETAXEL TRIHYDRATE LOADED SELF-ASSEMBLED NANOCARRIERS FOR TREATMENT OF HER2 POSITIVE BREAST CANCER
}

\author{
Nilesh R. Rarokar*, Pramod B. Khedekar \\ Nanotechnology Laboratory, Department of Pharmaceutical Sciences, Rashtrasant Tukadoji Maharaj Nagpur University, Nagpur, \\ Maharashtra, India-440033
}

\begin{abstract}
Human Epidermal Growth Factor Receptor 2-positive (HER2-positive) breast cancer tend to be more aggressive among all breast cancers. Breast cancers with HER2 gene amplification or HER2 protein overexpression are called HER2-positive. It tends to grow faster and are more likely to spread and come back compared to HER2-negative breast cancers. HER2 positive breast cancer is often treated with chemotherapy drugs called anthracylines (e.g. doxorubicine, epirubicine), taxanes (e.g. Docetaxel, peclitaxel) as well as some others, usually in combination of two or more chemotherapy drugs ${ }^{1}$ but the development of potential drug delivery system by using nanotechnology is also the important aspect for the proper treatment of HER2 positive breast cancer. The aim of this study was to develop DTX-loaded self assembled nanocarriers (SANs) for treatment of HER2 positive breast cancer and also to evaluate their efficacy to release the drug by controlled manner. SANs were prepared from a glyceryl monooleate, Pluronic $($ F127 $(0.5-1.5 \%$ w/v) and Pluronic ${ }^{\circledR}$ F68 (0.25-1.0 \%w/v) in different concentration with or without docetaxel trihydrate (DTX) (2.0\%w/v) by high pressure homogenization, before preparation compatibility of drug and polymers was studied by differential scanning calorimetry (DSC) and FTIR spectroscopy. Prepared SANs was then subject to different evaluation test particle size, zeta potential, \% entrapment efficiency, drug content, in vitro drug release study, measurement of $\mathrm{pH}$, and stability study. Particle size of SANs prepared with Pluronic ${ }^{\circledR}$ F127 was found in the range of $170 \mathrm{~nm}$ to $280 \mathrm{~nm}$ whereas SANs with Pluronic $\AA$ F68 was found between 200 to $240 \mathrm{~nm}$ and it shows more negative zeta potential value than $-30 \mathrm{mV}$. More than $90 \%$ of DTX was found to be entrapped in SANs formulations loaded with DTX $2.0 \%$ w/v. Drug released study revealed that formulation F9 containing $0.25 \%$ PF68 shows $89.59 \%$ release after $12 \mathrm{~h}$ and F5 containing $1.0 \%$ PF127 releases $96.56 \%$ drug after $12 \mathrm{~h}$. Results of one month stability study shows that the SANs formulations were found to be stable over a one month. Hence, the DTX-loaded SANs was act as an potential drug carrier to fulfill the demand of cancer therapeutics.
\end{abstract}

Keyword: self assembled nanocarriers, docetaxel trihydrate, breast cancer, Pluronic $®$

Article Info: Received 06 Oct, 2017; Review Completed 23 Oct, 2017; Accepted 25 Oct, 2017; Available online 15 Nov, 2017

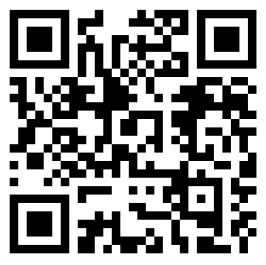

Cite this article as:

Rarokar NR, Khedekar PB, Formulation and evaluation of docetaxel trihydrate loaded self-assembled nanocarriers for treatment of HER2 positive breast cancer, Journal of Drug Delivery and Therapeutics. 2017; $7(6): 1-6$

DOI: http://dx.doi.org/10.22270/iddt.v7i6.1530

\section{*Address for Correspondence}

Nilesh Ramesh Rarokar, Nanotechnology Laboratory, Department of Pharmaceutical Sciences, Rashtrasant Tukadoji Maharaj Nagpur University, Nagpur, Maharashtra, India-440033. Telephone No.: +91-712-2500324, Fax No.: +91-712-2500355, Email: nileshrarokar@outlook.com

\section{INTRODUCTION}

Human Epidermal Growth Factor Receptor 2-positive (HER2-positive) breast cancer tend to be more aggressive among all breast cancers. Breast cancers with HER2 gene amplification or HER2 protein over expression are called HER2-positive. The HER2 gene makes HER2 proteins. HER2 proteins are receptors on breast cells. Normally, HER2 receptors help control how a healthy breast cell grows, divides, and repairs itself. But in about $25 \%$ of breast cancers, the HER 2 gene doesn't work correctly and makes too many copies of it 
(known as HER2 gene amplification). All these extra HER2 genes tell breast cells to make too many HER2 receptors (HER2 protein over expression). This makes breast cells grow and divide in an uncontrolled way. HER2-positive breast cancers tend to grow faster and are more likely to spread and come back compared to HER2-negative breast cancers.

Between 15 and 25 out of every 100 women with breast cancer (15-25\%) have HER2 positive cancers. Fewer men with breast cancer are thought to have HER2 positive cancers. There are some treatments available specifically for HER2-positive breast cancer. There are different groups of chemotherapy drugs. HER2 positive breast cancer is often treated with chemotherapy drugs called anthracylines (e.g. doxorubicine, epirubicine), taxanes (e.g. Docetaxel, peclitaxel) as well as some others, usually in combination of two or more chemotherapy drugs ${ }^{1}$ but the development of potential drug delivery system by using nanotechnology is also the important aspect for the proper treatment of HER2 positive breast cancer. There are number of nanoparticulate drug delivery system available for the delivery of anticancer agents but the Self-assembled nanocarriers (SANs) have more potential than the other drug delivery system.

SANs are bicontinuous cubic phase liquid crystals have many properties that make them appealing as a universal vehicle for drug delivery. These are nanoparticles, more accurately nanostructure particles, or self-assembled liquid crystalline particles with a solid-like rheology ${ }^{2}$. In recent years, SANs were considered as the drug nanocarrier due to their great potential as an alternative drug delivery system relative to liposome. The stability is another drawback in fabrication of liposome however colloidal dispersions of SANs can be stabilized by the addition of polymers. They also possess the potential for controlled delivery of actives, where diffusion is governed by the tortuous diffusion of the active through the "regular" channel structure of the cubic phase. SANs possess a sufficient average degree of molecular orientation in order to characterize by structural symmetry, and often form in aqueous surfactant system at relatively high ampiphile concentrations.

SANs especially made of binary systems, monooleinwater ${ }^{3}$. That can self-assemble into thermodynamically stable biocontinuous cubic liquid crystallize phases 4 . These are capable of loading lipophilic, hydrophilic, and amphiphilic drugs. Their three dimension nanostructure with hydrophobic and hydrophilic domains increases their importance in novel drug pharmaceutical drug delivery.

These systems include liquid crystalline aggregates or cross-linked gel networks that load, stabilize and ultimately deliver active ingredients. Incorporation of drugs into the complex internal domains of these structures can facilitate diffusion controlled release of drug into the surrounding external aqueous environment ${ }^{5-7}$. The large interfacial area can provide a complex diffusion pathway for sustained release of entrapped drug molecules, whereas lipid constituents are biocompatible, bioadhesive, and digestible ${ }^{8,9}$.
The aim of this study was to develop DTX-loaded SANs for treatment of HER2 positive breast cancer and also to evaluate their efficacy to release the drug by controlled manner.

\section{MATERIALS AND METHOD}

Docetaxel trihydrate (DTX) was obtained as a gift sample from Scino Pharmaceutical Pvt., Taiwan. Glyceryl monooleate was obtained from Otto Chemie., Mumbai (India). Pluronic $®$ F127 (PF127) obtained from Research Lab Fine Chem Industries, Mumbai(India), and Pluronic $®$ F68 (PF68) was obtained from Himedia Laboratory Pvt. Ltd. Water was purifiedon a Milli-Q system obtained from a Millipore ${ }^{\circledR}$ synergy system (Millipore, Billerica, Massachusetts, USA). All other chemicals used were of analytical grade.

\section{Preparation of SANs}

SANs were prepared by method described in our previous publication ${ }^{10}$ from a glyceryl monooleate and Pluronic $\AA$ F127 melt with or without drug. Glyceryl monooleate and Pluronic $\AA$ F127 were melted at $60^{\circ} \mathrm{C}$ until homogenous at a ratio of glyceryl monooleate to Pluronic ${ }^{\circledR}$ F127 of 9:1 (w/w). DTX was loaded by preparing drug solution in required volume of ethanol for dissolution. To this mixture $5.0 \mathrm{ml}$ of ethanol was added as a hydrotropic solvent.

To prepare the self-assembled nanocarriers dispersion, the low viscosity homogenous melt was either added drop wise or injected into excess water such that the concentration of lipid in the sample was approximately $8-10 \%$ (w/w) with continuous stirring on magnetic stirrer and volume was made up to $100.0 \mathrm{ml}$ with distilled water. Samples were allowed to equilibrate at room temperature for overnight. The samples were then homogenized for 2 min using homogenizer at 1500-2000 rpm because much more homogenization may hamper the cubic crystal structure. Sterilization was done in autoclave at $121^{\circ} \mathrm{C}, 15 \mathrm{lb}$ pressure for $20 \mathrm{~min}$. Prepared self-assembled nanocarriers dispersion stored in glass vial at room temperature. Same procedure was repeated for preparation of self-assembled nanocarriers with Pluronic ${ }^{\circledR}$ F68 as shown in Table. 1. Though Pluronic ${ }^{\circledR}$ have a gelling property, it does not show any type of gelation during self-assembled nanocarriers formation as it was used in very small concentration.

\section{Drug-Excipients Compatibility Studies}

\section{Thermal Analysis}

The drug, the polymers, and their physical mixtures with DTX were analyzed by differential scanning calorimetry (DSC). Open pan DSC measurements were carried out using a DSC Q20 (TA Instruments Inc., New Castle, DE) with a sample size of approximately $5 \mathrm{mg}$ weighed into each aluminum pans. Samples were heated at $10^{\circ} \mathrm{C} /$ min from 0 to $400^{\circ} \mathrm{C}$. Nitrogen at a flow rate of $40 \mathrm{~mL} /$ min was used as a purge gas in DSC analyses. The results were analyzed using the Universal Analysis software version 4.5A; build 4.5.0.5 (TA Instruments, Inc., New Castle, DE, USA). 
Table 1: SANs dispersion prepared with Pluronic F127 and Pluronic F68

\begin{tabular}{|c|c|c|c|c|c|c|c|}
\hline $\begin{array}{c}\text { Sr. } \\
\text { No. }\end{array}$ & Formulation & $\begin{array}{c}\text { Glyceryle } \\
\text { monooleate }(\% \mathrm{v} / \mathrm{v})\end{array}$ & $\begin{array}{c}\text { Pluronic F127 } \\
(\% \mathrm{w} / \mathrm{v})\end{array}$ & $\begin{array}{c}\text { Pluronic F68 } \\
(\% \mathrm{w} / \mathrm{v})\end{array}$ & $\begin{array}{c}\text { Ethanol } \\
(\% \mathrm{v} / \mathrm{v})\end{array}$ & $\begin{array}{c}\text { DTX \% } \\
(\mathrm{w} / \mathrm{v})\end{array}$ & $\begin{array}{c}\text { Dist. } \\
\text { water }\end{array}$ \\
\hline 01. & $\mathrm{~F}_{1}$ & 9.0 & 0.5 & - & 5.0 & - & q.s. \\
\hline 02. & $\mathrm{~F}_{2}$ & 9.0 & 1.0 & - & 5.0 & - & q.s. \\
\hline 03. & $\mathrm{~F}_{3}$ & 9.0 & 1.5 & - & 5.0 & - & q.s. \\
\hline 04. & $\mathrm{~F}_{4}$ & 9.0 & 0.5 & - & 5.0 & 2.0 & q.s. \\
\hline 05. & $\mathrm{~F}_{5}$ & 9.0 & 1.0 & - & 5.0 & 2.0 & q.s. \\
\hline 06. & $\mathrm{~F}_{6}$ & 9.0 & - & 0.25 & 5.0 & - & q.s. \\
\hline 07. & $\mathrm{~F}_{7}$ & 9.0 & - & 0.5 & 5.0 & - & q.s. \\
\hline 08. & $\mathrm{~F}_{8}$ & 9.0 & - & 1.0 & 5.0 & - & q.s. \\
\hline 09. & $\mathrm{~F}_{9}$ & 9.0 & - & 0.25 & 5.0 & 2.0 & q.s. \\
\hline 10. & $\mathrm{~F}_{10}$ & 9.0 & - & 0.5 & 5.0 & 2.0 & q.s. \\
\hline
\end{tabular}

*Value given for $100 \mathrm{~mL}$

\section{FTIR Spectroscopy}

To determine any possible interactions, the physical mixtures of the drug and the polymers were analyzed using the Fourier transformed infrared (FTIR) spectroscopy.

Briefly, the samples were dried in a hot air oven at $50^{\circ} \mathrm{C}$ for $2 \mathrm{~h}$. The samples were mixed with $\mathrm{KBr}$ and subject to scanning in the range of 400 to $4000 \mathrm{~cm}-1$. Infrared spectra of drug, polymer and their physical mixture were obtained from an FTIR spectrophotometer (Model: IR Prestige-21, Shimadzu, Japan) equipped with an attenuated total reflectance (ATR) accessory. The influence of the residual moisture was theoretically removed by subjecting the samples to vacuum drying before obtaining any spectra. Each sample analysis included 45 scans, at a resolution of $4 \mathrm{~cm}^{-1}$ from 4500 to $400 \mathrm{~cm}^{-1}$. The shifts in the spectra of the drug in the presence of polymers and other components were investigated to determine physical interactions between the drug and the polymers, if any.

\section{Evaluation of SANs}

\section{Particle size determination ${ }^{10}$}

Particle size analysis of dispersions was performed using a Zeta sizer 3000 PCS (Malvern Instr., England) equipped with a $5 \mathrm{~mW}$ helium neon laser with a wavelength output of $633 \mathrm{~nm}$. Measurements were made at $25^{\circ} \mathrm{C}$, angle $90^{\circ}$, run time at least $40-80 \mathrm{sec}$ and water used as a dispersant. Data interpreted by method of cumulants.

\section{Zeta potential measurement $^{10,}$}

Zeta potential measurement of SANs dispersion was performed by using Zeta Potentiometer (Malvern Instr., England) equipped with a $5 \mathrm{~mW}$ helium neon laser with a wavelength output of $633 \mathrm{~nm}$. Measurements were made at $25^{\circ} \mathrm{C}$, angle $90^{\circ}, 10-15$ runs and water used as a dispersant.

\section{Entrapment efficiency ${ }^{11}$}

The sample of SANs dispersion was transferred to the centrifuge tubes and put to $1500 \mathrm{rpm}$ for $2 \mathrm{~h}$. Nonentrapped drug or free drug in solution leaked outside the sub-tubes, making it possible to measure its concentration in solution, and thus allowed the deduction of the drug encapsulated in SANs. That UV absorbance was used to compute $\mathrm{Ct}$ (namely, total concentration) and the UV absorbance of DTX contained in filtrate after centrifuge was used to compute Cf (namely, filtrate concentration). Thus, the \% entrapment efficiency was calculated as follows:

$$
\% \mathrm{EE}=[(\mathrm{Ct}-\mathrm{Cf}) / \mathrm{Ct}] \times 100
$$

\section{Drug content of SANs ${ }^{11,12}$}

Each formulation $(1.0 \mathrm{ml})$ equivalent to $20 \mathrm{mg}$ was taken in a $100 \mathrm{ml}$ volumetric flask diluted with PBS (pH 7.4) and shaken to until it gets dissolve otherwise sonicated for $30 \mathrm{~min}$. The solution was filtered through whattman filter paper, $1 \mathrm{ml}$ of above filtrate was pipette out and diluted to $10 \mathrm{ml}$ with phosphate PBS ( $\mathrm{pH} 7.4$ ). The content of the drug was estimated spectrophotometrically by using standard curve plotted at $220 \mathrm{~nm}$.

\section{In vitro drug release study ${ }^{11}$}

Drug release from SANs dispersion was carried out by using Franz diffusion cell. It consists of two compartment i.e., Donor compartment (cell cap) and receptor compartment. Previously activated semi permeable membrane (cellophane membrane) is placed between these two compartments. Dispersion was added into the donor compartment above cellophane membrane. Receptor compartment consist of stirring bar and sampling port having $18 \mathrm{ml}$ capacity.

The receptor compartment containing $18 \mathrm{ml}$ PBS solution ( $\mathrm{pH} 7.4$ ) and maintained temperature at $37 \pm 0.5$ ${ }^{0} \mathrm{C}$ at predetermined time points, $1 \mathrm{ml}$ of sample was withdrawn from the receptor compartment, replacing the sampled volume with same volume of PBS pH 7.4 after each sampling for a period of 10-12 $\mathrm{h}$. The samples were suitably diluted and measured spectrophotometrically at $220 \mathrm{~nm}$. The concentration of drug was determined from a previously constructed calibration curve.

\section{Determination of $\mathbf{p H}$}

The $\mathrm{pH}$ of SANs dispersions was determined at room temperature using digital $\mathrm{pH}$ meter, model NIG-333. $\mathrm{pH}$ meter was calibrated using $9.2 \mathrm{pH}$ and $4.0 \mathrm{pH}$ buffer solutions. All the studies were repeated in triplicate with good agreement being found between measurements. 


\section{Stability study}

The stability study of selected formulation was done at $40^{\circ} \mathrm{C}$ with $75 \% \mathrm{RH}$ and room temperature and also in freezing temperature. The test parameters such as integrity, phase separation, $\mathrm{pH}$ measurement was carried out as a stability parameter after a specific time interval and drug precipitation were determined at every week till one month. Particle size determination was conducted at different time interval in order to evidence possible variations in mean diameter of SANs over time of one month.

\section{RESULT AND DISCUSSION}

\section{Drug-Excipients Compatibility Studies}

\section{Thermal Analysis}

The DSC thermogram of pure DTX showed a sharp endothermic peak at $\sim 169^{\circ} \mathrm{C}$, corresponding to DTX melting point (thermograms not shown). Additionally, the DSC thermograms of Pluronic $\AA$ F127 and Pluronic ${ }^{\circledR}$ F68 revealed sharp endothermic peaks at temperatures of $\sim 58$ and $\sim 56^{\circ} \mathrm{C}$, respectively.

The DSC analysis of the physical mixtures, DTX: Pluronic $\AA$ F127 (1:1), and DTX: Pluronic $₫$ F68 (1:1), revealed a negligible and a non-significant change in the thermal behavior of DTX in the presence of these polymers. Additionally, the melting signals (endotherm) of Pluronic $₫$ F127, and Pluronic $₫$ F68 were clearly distinguishable in the physical mixtures of the respective polymers with DTX. The absence of any other endothermic peak over the entire temperature range thus excluded any physical interaction or obvious incompatibility between the drug and the polymers. The DSC results thus indicated the suitability of these polymers to be used in the prepared formulations.

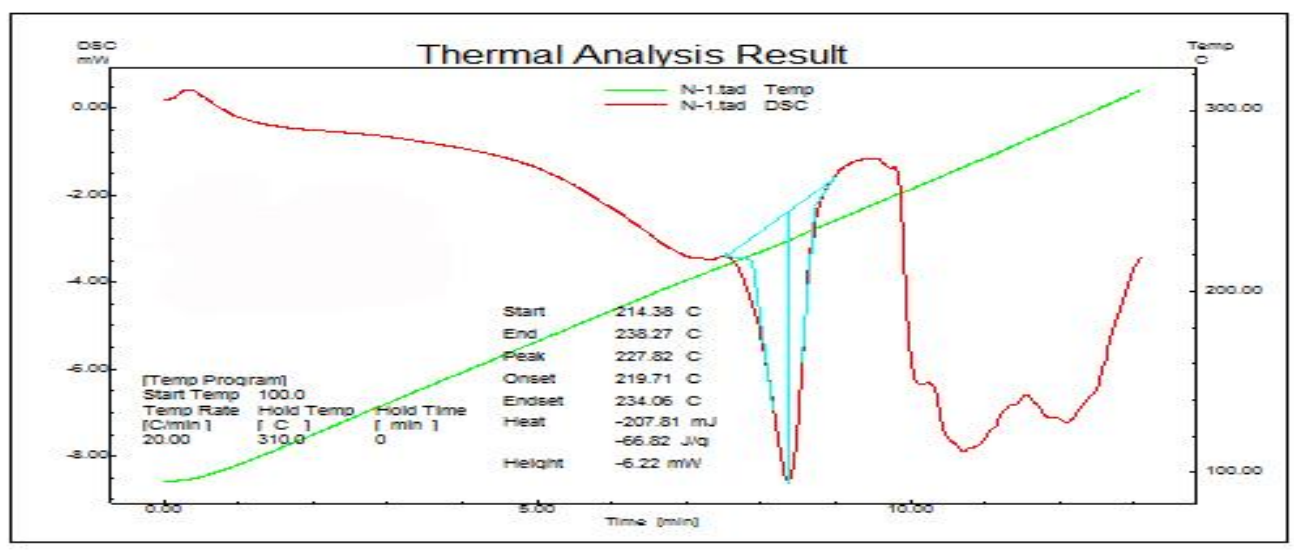

(A)

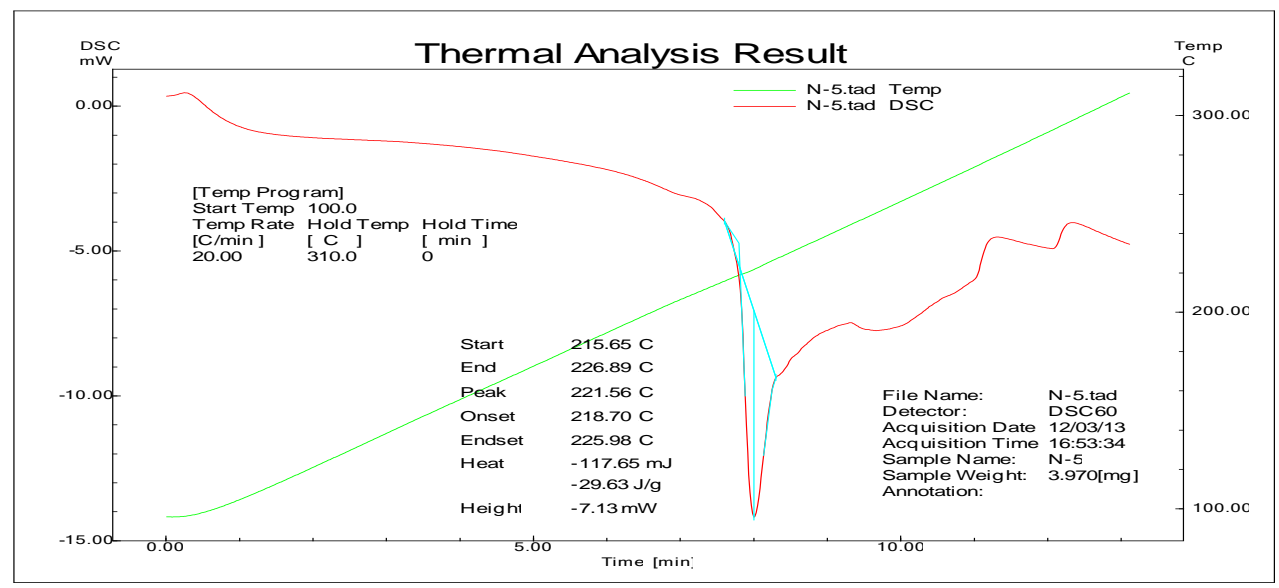

(B)

Figure1: DSC thermogram for DTX (A), physical mixture of DTX and polymers (B)

\section{Fourier Transform Infrared (FTIR) Spectroscopy}

The FTIR spectra for DTX, Pluronic $®$ F127 and Pluronic ${ }^{\circledR}$ F68 individually, the binary mixtures of the drug with individual polymers, as well as a mixture of the drug with all the polymers, are shown in Fig. 2. The
FTIR analysis did not show any significant difference between the individual spectra and those obtained from their physical mixtures. The results obtained after the FTIR study thus indicated that there was no positive evidence for the interaction between Docetaxel trihydrate and the used polymers. 


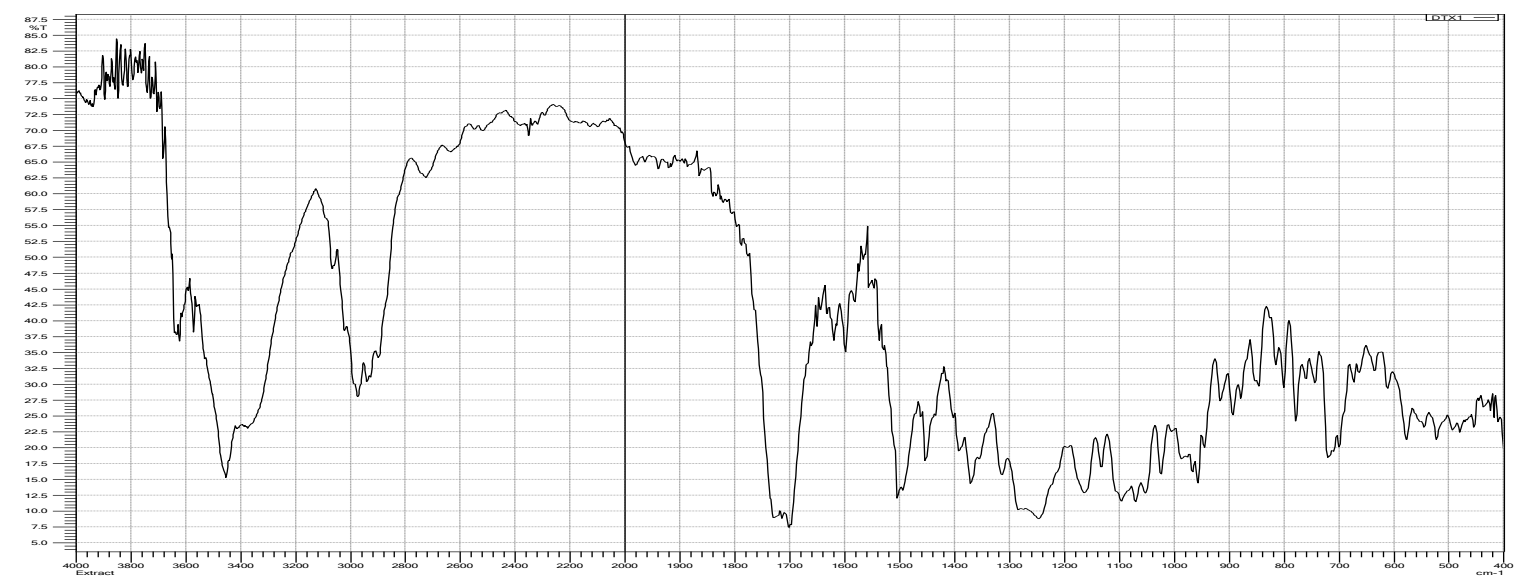

(A)

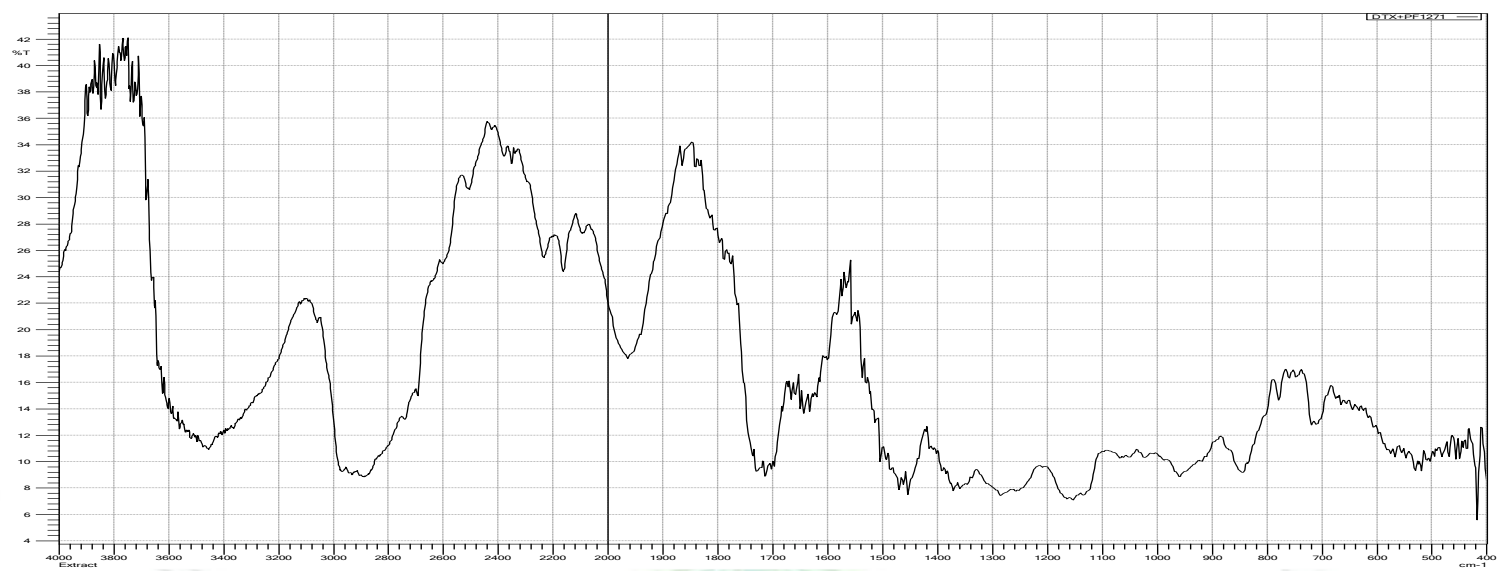

(B)

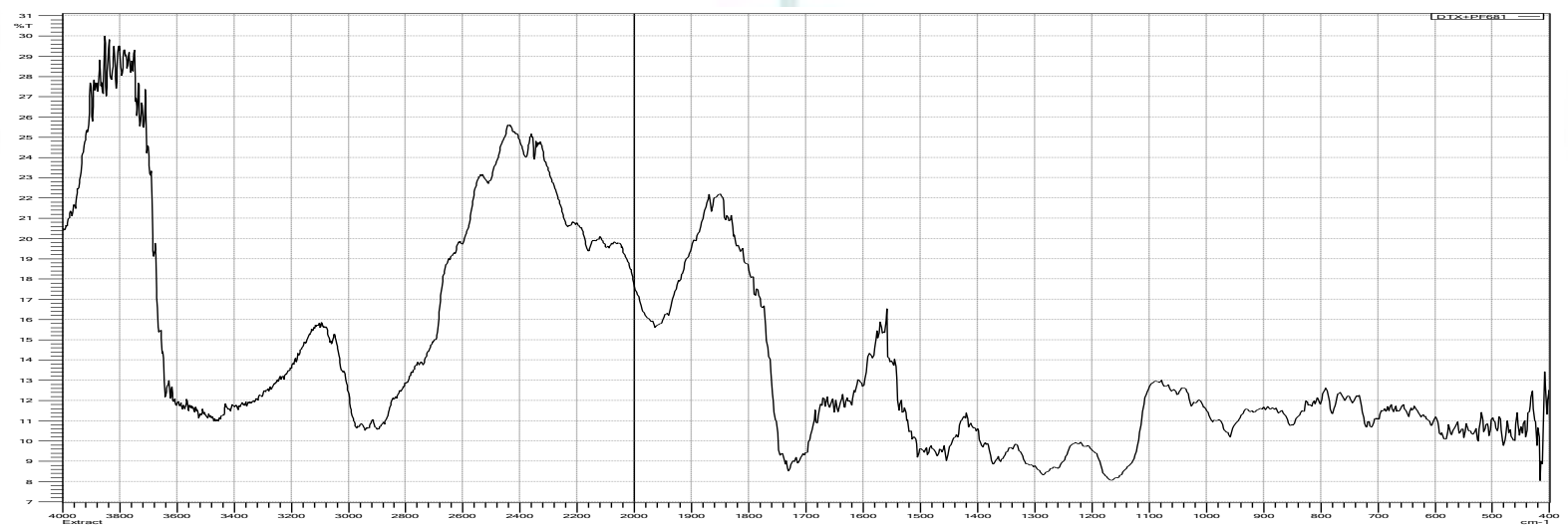

(C)

Figure 2: FTIR-spectra of DTX (A), DTX-Pluronic ${ }^{\circledR}$ F127 (B) and DTX-Pluronic $®$ F68 (C)

\section{Evaluation of SANs}

\section{Particle size}

Particle size of SANs F1 F2 F3 F4 F5 prepared by Pluronic ${ }^{\circledR}$ F127 in the concentration $0.5 \%, 1.0 \%, 1.5 \%$ without drug and $0.5 \%, 1.0 \%$ with drug DTX was found to be in the range of $170 \mathrm{~nm}$ to $280 \mathrm{~nm}$. While Particle size of SANs F6, F7, F8, F9, F10 prepared by Pluronic ${ }^{\circledR}$ F68 in the concentration $0.25 \%, 0.5 \%, 1.0 \%$, $1.5 \%$ without drug and $0.25 \%$ with drug DTX were found to be in the range of $200 \mathrm{~nm}$ to $240 \mathrm{~nm}$.

\section{Zeta Potential}

Particles with zeta potentials more negative than $-30 \mathrm{mV}$ are normally considered stable. The results of zeta potential measurement of SANs dispersion revealed that formulation $\mathrm{F} 1$ and $\mathrm{F} 7$ shows more negative zeta potential value about $-54.1 \mathrm{mV}$ and $-47.4 \mathrm{mV}$ respectively.

\section{Determination of pH}

Formulations F1, F2, F3, F4, F5 and F6, F7, F8, F9, $\mathrm{F} 10$ shows $\mathrm{pH}$ in the normal range of 6.5 to 7.5 whereas pH of formulation prepared by Pluronic $\AA$ F68 (F6-F10) was found to be more than that of Pluronic $₫$ F127 (F1F5).

\section{Entrapment efficiency}

The drug entrapment efficiency is an important parameter for drug delivery systems. The \% entrapment efficiency of the DTX loaded SANs was found to be $95.67 \pm 2.0,94.74 \pm 2.0$ and $91.95 \pm 1.8(\% \mathrm{w} / \mathrm{w})$ for 
formulations F4, F5 and F10 respectively. These results indicate that most of the DTX was encapsulated in the SANs.

\section{Drug content}

The results obtained in drug content determination for different formulations revealed that the drug content F4, F5 and F10 was found to be more than $95 \%$ to the amount of drug loading. It means that, the entire drug was well uniformly distributed. The percentage relative standard deviation (\% RSD) is less than $2 \%$ indicates the reproducibility of process used for further formulation.

\section{In vitro drug release study}

On the basis of results obtained during above evaluation parameters the formulations containing $1.0 \%$ Pluronic $\AA$ F127 and $0.25 \%$ Pluronic $\circledR$ F68 were selected for the further study of drug release. The results of drug released study revealed that formulation F9 containing $0.25 \%$ PF68 shows $89.59 \%$ release after $12 \mathrm{~h}$ and F5 containing $1.0 \%$ PF127 releases $96.56 \%$ drug after $12 \mathrm{~h}$, it means that formulation F9 prepared with $0.25 \%$ Pluronic $®$ F68 shows more sustained release as compared to F5 containing $1.0 \%$ PF 127 and might have efficiency to releases drug more than $12 \mathrm{~h}$ however, plane DTX-solution shows complete release within $4 \mathrm{~h}$ as shown in Figure 3.

\section{Stability Study}

The SANs dispersion prepared by both Pluronic $®$ F127 and Pluronic ${ }^{\circledR}$ F68 appears milky white and odorless. After production and elimination of large particles by filtration, dispersion was stored in glass vials at room temperature in dark, $40^{\circ} \mathrm{C}$ with $75 \% \mathrm{RH}$ and also at freezing temperature. In order to assess the physical stability of SANs dispersion, organoleptic and morphological aspects such as phase separation and formation of precipitates were investigated as a function of time. The organoleptic and morphological aspects of SANs dispersion were found to be unchanged with time; and SANs dispersion was found to be free from phase separation phenomena for more than one month.

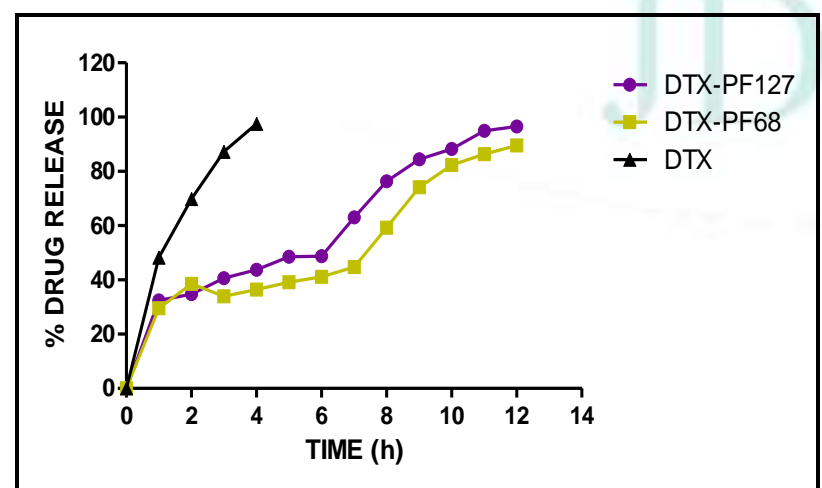

Figure 3: \% drug release from DTX-loaded SANs

Results of one month stability study shows that $\mathrm{pH}$ of formulations prepared using Pluronic ${ }^{\circledR}$ F127 and Pluronic ${ }^{\circledR}$ F68 showed slightly decreases in $\mathrm{pH}$ after one month as compared to $\mathrm{pH}$ values at initial time. But not significant change was observed after one month storage at at different storage condition. According to results obtained for formulations F1, F2, F3 the very slight change in particle size was observed and did not exceed $290.3 \mathrm{~nm}$ while formulations F6, F7, F8 also shows very less changes in particle size and not exceed $233.4 \mathrm{~nm}$.

\section{CONCLUSION}

The Docetaxel trihydrate loaded SANs prepared by PF127 was found to be more stable and effective than that of SANs prepared by PF68. The fabrication of nanoparticulate drug delivery containing SANs is the need of breast cancer therapy. To overcome the drawbacks concern with the bioavailability of docetaxel trihydrate, the formulation of SANs delivery system was found to be best approach in the designing of novel controlled release drug delivery system. The DTX-loaded SANs was act as an potential drug carrier to fulfill the demand of cancer therapeutics.

\section{CONFLICT OF INTEREST}

All contributing authors declare no conflicts of interest

\section{REFERENCES}

1. Sevcikova K, Vertakova-Krakovska B, Spanik S, Neoadjuvant Treatment in Patients with HER2-Positive Breast Cancer. ISRN Oncology, 2013; 1-8.

2. Rizwan SB, Boyd BJ, Rades T, Hook S, Bicontinuous cubic liquid crystals as sustained delivery systems for peptides and proteins, Expert Opinion on Drug Delivery, 2010; 7(10):11331144

3. Bei D, Marszalek J, Youan BC, Formulation of Dacarbazine Loaded Cubosomes-Part I: Influence of Formulation Variables, AAPS Pharm Sci Tech. 2009; 10(3):1032-1039.

4. Fontell, K., Mandell, L., and Ekwall, P., "Isotropic Mesophases in Systems Containing Amphiphilic Compounds," Acta Chem. Scand. 1968; 22:3209-23.

5. Shah JC, Sadhale Y, Chilukuri DM, Cubic phase gels as drug delivery systems, Adv Drug Deliver Rev. 2001; 47:229-250.

6. Burrows R, Collett JH, Attwood D, The release of drugs from monoglyceride-water liquid crystalline phases, Int. J. Pharm. 1994; 111:283-293.

7. Drummond CJ, Fong C, Surfactant self assembly objects as novel drug delivery vehicles, Current Openion Colloid Interface Science (2000) 449-456.

8. Barauskas J, Johnsson M, Joabsson F, Tiberg F. Cubic phase nanoparticles (cubosome): principles for controlling size, structure, and stability. Langmuir 2005; 21(6):2569-77.

9. Barauskas J, Johnsson M, Tiberg F. Self-assembled lipid superstructures: beyond vesicles and liposomes. Nano Lett. 2000; 5(8):1615-19.

10. Rarokar NR, Saoji SD, Raut NA, Taksande JB, Khedekar PB, Dave VS. Nanostructured Cubosomes in a Thermoresponsive Depot System: An Alternative Approach for the Controlled Delivery of Docetaxel. AAPS PharmSciTech. 2015; 17:436-445.

11. Fong W, Hanley T, Boyd B, Stimuli responsive liquid crystals provide 'on-demand' drug delivery in vitro and in vivo, $\mathrm{J}$. Control. Release. 2009; 135:218-226.

12. Dong YD, Larson I, Hanley T, Boyd BJ, Bulk and dispersed aqueous phase behaviour of phytantriol: effect of vitamin $\mathrm{E}$ acetate and F127 polymer on liquid crystal nanostructure, Langmuir, 2006; 22:9512-9518.

13. Luzzati V, Tardieu A, Gulik-Kryzwicki T, Rivas E, RiessHusson F, Nature (London) 1968; 220:485-487.

14. Gaikwad V, et al. Formulation and evaluation of In-Situ gel of metoprolol tartrate for nasal delivery. J Pharm Res. 2010; 3:788793.

15. Maghsoudi A, Shojaosadati SA, Vasheghani Farahani E. 5hFluorouracil-loaded BSA nanoparticles: formulation optimization and in-vitro release study. AAPS Pharm Sci Tech. 2008; 9(4):1092-6. 